\title{
Ciencias Sociales, Sociología y pobreza en Guatemala
}

EDGAR S. G. MENDOZA

Introducción: ¿Por qué se debe estudiar la pobreza?

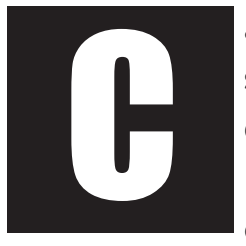

ada campo disciplinar dentro de las Ciencias Sociales tiene su propia historia, perspectivas teóricas, obras, grados de desarrollo metodológico y empírico, marco institucional y un cuerpo bibliográfico que lo respalda. Dentro de este campo de conocimiento tenemos la ciudadanía y la democracia que son temas importantes para Centroamérica. La interrogante primaria de este artículo: ¿Cuál es el estado del arte de la producción académica-científica regional acerca de estos temas? Una posible respuesta sería conocer la investigación sobre pobreza en Guatemala y como ella evidencia y/o muestra la desigualdad social, exclusión y marginalidad de los grupos sociales más pobres, ofreciendo caminos para la construcción de una ciudadanía. Los temas sobre la ciudadanía y democracia: La primera entendida como un conjunto de derechos y deberes (civiles, políticos y sociales) con responsabilidades dentro de una sociedad y libertades individuales y la segunda como una forma de gobierno que permite libertad, igualdad y participación política, son aspectos de relevantes para América

\footnotetext{
* Doctor en Ciencias Sociales por la UNICAMP de São Paulo Brasil, Maestría en Antropología Social por la Universidad de Brasilia. Actualmente es investigador en el Instituto de Investigaciones de la Escuela de Historia de la Universidad de San Carlos de Guatemala. Académico de Número de la Academia de Geografía e Historia de Guatemala. Asimismo, miembro de la Junta Directiva de la Asociación Latinoamericana de Sociología -ALAS- período 2003-2005. Endereço eletrônico: esgmendoza@yahoo.es
} 
Central. La ciudadanía y la democracia en Guatemala deben de tener cuatro aspectos: a) estabilidad económica, b) combate a la pobreza y desigualdad, c) práctica político-democrática y d) apoyo popular y legitimidad del gobierno en le poder. A pesar de la importancia de todos los aspectos, no interesa en este artículo el aspecto de la pobreza y la desigualdad.

Es así que la investigación que se desarrolló, ahora conformada como artículo pretendió comprender desde una perspectiva sociológica el Estado del arte de los estudios de pobreza en Guatemala entre 1980 y 2004 siendo un período de gestación de lo que será el campo de conocimiento de la pobreza en la actualidad. La justificación del trabajo se debe a la ausencia de una investigación que trate de entender el desarrollo del tema en las Ciencias Sociales en Guatemala y que demuestre su importancia a través de experiencias teóricas y metodológicas. Cada vez más el tema de pobreza cobra importancia en los años recientes desde puntos de vista diferentes como el Estado, centros de investigación, universidades, las Ongs y la Cooperación Internacional. Es así que es necesaria una investigación exploratoria del tema. Se puede decir que la investigación sobre la pobreza no ha sido sistemática ni continua debido al proceso social y político que ha vivido el país, donde su democracia ha sido amenazada. No obstante se afirma con toda certeza que existe un corpus bibliográfico heterogéneo y considerable entre 1980-2004.

Analizar los estudios de pobreza lleva implícito una serie de preguntas secundarias que direccionan la investigación: ¿Es posible ver la ciudadanía y la democracia a través de los estudios de pobreza?, ¿Qué se investiga?, ¿Qué perspectivas teóricas utilizan?, ¿Qué tipo y cuáles estudios son?, ¿Cuántas investigaciones hay?, ¿Qué instituciones están involucradas?, ¿Quiénes son los investigadores o equipos de investigación?, ¿Qué áreas geográficas se estudian?, ¿Qué disciplinas los estudian?, ¿Qué aspectos temáticos son?, ¿Qué metodologías se emplean?, ¿Cuáles son sus alcances y limitaciones?, ¿Qué logran y que proponen?, ¿Puede pensarse en una 
sociología de la pobreza?.

La investigación tuvo como objetivos: a) hacer el mapeo del Estado de la cuestión de los estudios de pobreza en Guatemala en la delimitación temporal de 1980 a 2004, b) realizar un balance de las tendencias teóricas y metodológicas de los estudios en los últimos 20 años, c) La investigación trata de ser un apoyo bibliográfico para futuras investigaciones e investigadores interesados en el tema de la pobreza en Guatemala, d) señalar la historicidad e importancia de los estudios de pobreza dentro de las Ciencias Sociales guatemaltecas; incorporándolos a los temas tradicionales como la cuestión étnica, religión, Estado, urbanismo, salud, educación, campesinado, cultura popular y otros, e) ver los estudios de pobreza como posibles caminos de construcción de ciudadanía.

Entre los objetivos específicos tenemos: a) conocer perspectivas teóricas y áreas geográficas de los estudios, b) determinar si existen denominadores comunes y caracterizar los niveles de análisis, si son macro-sociales o micro-sociales, c) caracterizar la metodología de recolección de datos, si cuantitativos o cualitativos, d) conocer la estructura institucional y de financiamiento de las investigaciones de pobreza, estatales, Cooperación Internacional, privados, y las Ongs, e) conocer sus ausencias, déficit, aportes y avances, f) analizar los estudios de pobreza sin perder de vista su contexto histórico social, g) si los trabajos de pobreza contribuyen a la búsqueda de derechos, garantías y deberes de ciudadanía.

Se está conciente que la pobreza es la preocupación final de este artículo, no se trata entonces de presentar nuevas definiciones de la categoría ni métodos de medición. Mas bien el objetivo es más modesto, nos interesa comprender el desarrollo de un campo disciplinar como lo es la pobreza en Guatemala. Es así que toda investigación tiene sus límites, debo apuntar que la bibliografía sobre pobreza es bastante amplia e inevitablemente mereció seleccionar una muestra de los trabajos más representativos e innovadores, no sólo en las dos décadas analizadas, sino 
también en sus temas. Estamos concientes que existen autores y obras, talvez importantes, sin embargo no ignorados, pero no era posible tomarlos en consideración a todos, ya que todo estudio necesita de recortes.

En el artículo no se pretende discutir exhaustivamente cada uno de los trabajos sobre pobreza, sino que se intenta entenderlos en su conjunto y perspectivas más globales pero al mismo tiempo puntuales. De igual forma debo indicar que no todo el material está publicado. Asimismo el corto tiempo de la investigación no fue posible agotar la amplia bibliografía sobre pobreza.

Apoyándome en el mapeo desarrollado en la investigación sobre pobreza, se puede proponer como estructura de argumentación que: a) Al analizar a los grupos vulnerables más pobres, se puede mostrar su situación de ciudadanía, b) la existencia de estudios macro-sociales y microsociales conforman todo el campo científico de la pobreza y c) que han existido cinco tendencias teórico-metodológicas en el análisis de la pobreza cada una en su momento histórico-teórico. La teoría del desarrollo y dependencia, teoría de la marginalidad, economía informal, cultura de la pobreza y en los años noventa las propuestas de exclusión social de organismos multilaterales como Banco Mundial BM, Banco Interamericano de Desarrollo BID y el Programa de Naciones Unidas para el Desarrollo PNUD, que colocaron el tema de la pobreza como agenda de investigación e inversión para los países en vías de desarrollo en un contexto de globalización.

El artículo se divide en cinco partes: La primera trata de una relación entre la sociología y la pobreza, resaltándose la importancia del contexto histórico, político, económico y social para comprenderla. La segunda, consiste en la importancia del campo disciplinar de la pobreza dentro de las Ciencias Sociales y como algunos estudios considerados clásicos sin ser necesariamente de pobreza la reflejan en su investigación. La tercera, se refiere a los estudios generales sobre la pobreza, que permiten una idea del 
tema en el país. La cuarta, se presentan estudios de caso con diversos temas estudiados. Finalmente las conclusiones que se obtuvieron se apoyan en la muestra estudiada. De igual forma en base a la investigación desarrollada se proponen por separado cuatro tesis equivocadas de la comprensión de la pobreza en Guatemala tanto a nivel estatal como académico.

\section{Sociología y pobreza}

En la búsqueda de inspiración teórica en la teoría sociológica para el estudio de la pobreza hay que consultar autores como: Simmel (1986, p. 513, 520) que en 1906 escribió un texto con el titulo de El pobre definido como "Aquel cuyos recursos no alcanzan a satisfacer sus fines y alivio de sus necesidades, el pobre, sociológicamente es el individuo que recibe socorro a causa de esa falta de recursos", el tipo ideal de pobre de Simmel no dista mucho de la definición actual.

Para el análisis de los estudios de pobreza en Guatemala me apoyé en el esquema teórico de Karl Mannheim que publica, El problema de una Sociología del conocimiento (1967) [1925] texto que indica que las posiciones intelectuales y los conocimientos teóricos e ideas aparecerían en determinadas épocas y condiciones sociales concretas, como sería el caso de la importancia de la ciudad en la revolución industrial y el surgimiento del modo de producción capitalista y para nuestro caso la pobreza a nivel mundial.

Según Mannheim una Sociología del conocimiento examina el problema de cómo surgen varios estilos de pensamiento y cómo están enraizados en una realidad histórico-social subyacente, existiendo una correlación con ciertas tendencias incorporadas por los estratos sociales, o sea una posición intelectual relacionada con clase social (ibid., p. 70-73). Es en parte, teoría y método histórico-sociológico de investigación, siendo una investigación, empírica y epistemológica. El por qué de la utilización del es- 
quema de Mannheim se debe a que nos permite entender el desarrollo de los históricamente pobres con siglos de explotación desde la conquista, colonia, siglo XIX hasta el presente siglo. Es así que la ponencia analiza los estudios de pobreza dentro de un contexto histórico, pero no necesariamente se describe una historia completa del país, sino que nos hemos limitado a lo que nos pareció indispensable de mencionar sin que necesariamente se siga una secuencia histórica no exhaustiva de los últimos 20 años.

Con todo, para Mannheim, la Sociología del conocimiento se encuentra dentro de una secuencia histórico social con conflictos y tensiones de los grupos que tiene el poder conservando formas políticas y sociales; cada grupo en el poder tiene sus sistemas de pensamiento en un medio social definido. En Guatemala, los diversos planes y políticas económicas propuestas por los grupos de poder desde la colonia hasta hoy han propiciado un empobrecimiento del país y de sus habitantes negando en su mayoría, la participación, derechos y deberes. El esquema de Mannheim me permitió comprender un campo intelectual de estudio de la pobreza.

Existe una respetable bibliografía que define la pobreza, es por ello que no entraré en este momento a una discusión altamente desarrollada por otros autores. ${ }^{1}$ No obstante, en esta investigación la pobreza es considerada como polisémica, o de varios significados, manifestaciones y ángulos tanto para los investigadores como para instituciones y disciplinas que la estudian. De igual forma la pobreza tiene múltiples dimensiones en la vida social, así mismo es un tema sincrético que no puede ser estudiado sin tomar en cuenta el desarrollo de otros campos de conocimiento.

\footnotetext{
1 Pueden ser consultados Atkinson La pobreza. Disponible en: <www.eumed.net/cursecon/textos/atkinson-lapobreza.htm>. Acceso en: 15 jun. 2004. Lok-Dessallien Review of Poverty Concepts and Indicators. Disponible en: <www.undp/poverty/ publications/pov_red>. Acceso en: 20 jul. 2004. Novak (1997), Rello (2001), Spicker (2003).
} 
La polisemia de la pobreza produce una serie de problemas metodológicos y de investigación a nivel mundial ya que existen diversas formas de estudiarla, tanto en perspectivas disciplinares-teóricas como metodológicas. En Guatemala existen estudios económicos que cuantifican la pobreza, pero simultáneamente otros se dedican a estudios de caso y tiene como trasfondo la pobreza. ¿Cómo resolverlo? Una posible solución fue seleccionar una muestra con cuatro criterios: a) temas, b) perspectivas disciplinares, c) innovación y d) décadas.

\section{La Ciencias Sociales y la pobreza en Guatemala}

Se puede asegurar que las Ciencias Sociales en Guatemala tradicionalmente se han caracterizado por el estudio de las clases sociales subalternas, o sea la pobreza ha sido el contexto substantivo y general. Esto ha permitido un sin numero de investigaciones desde disciplinas como la Antropología, Arqueología, Arquitectura, Ciencia Política, Economía, Historia y Sociología; teniendo cada una sus propios esquemas de análisis y conceptos. Siguiendo a Mannheim, se debe tener claro que cada país tiene sus especificidades y realidades concretas que determinan con frecuencia las líneas de investigación, predominio de ciertos objetos de estudio y orientaciones teóricas que han sido aplicadas a particularidades locales o nacionales dependiendo de sus contextos históricos sociales.

Las Ciencias Sociales tienen su propio desarrollo, ritmo y caminos. Claro está dependiendo de la realidad social que quieran comprender. La historia de las Ciencias Sociales en Guatemala, ha sido interrumpida por los gobiernos autoritarios y dictaduras militares provocando un éxodo de intelectuales, situación que pone en entredicho la ciudadanía y democracia. Sin embargo a pesar de ello, algunos temas se han convertido en tradicionales en las ciencias nacionales, pero al mismo tiempo existe tedesde varias perspectivas disciplinares atravesando varios temas, radicando ahí su 
importancia.

La pobreza en Guatemala se le considera históricamente estructural que ha adquirido diferentes formas en el transcurso del tiempo. Su mantenimiento crónico se debe a políticas económicas y sociales desiguales y de exclusión. Guatemala es una sociedad que ha sufrido un proceso de empobrecimiento crónico desde la conquista hasta nuestros días. En la actualidad su población es de 11 millones de personas, son varios los grupos sociales que están en situación de pobreza y extrema pobreza, predominando los grupos indígenas en el área rural. En relación a este último, desde la Revolución de 1944 el Estado ha tenido un interés por los grupos indígenas, la fundación del Instituto Indigenista Nacional en 1945 basado en la política de integración del indígena a la sociedad; permitió que la Antropología convirtiera a los indígenas en su objeto-sujeto de estudio tradicional que continua hasta hoy, con estudios micro-sociales, donde la pobreza no es su tema central de investigación, si bien que los indígenas están inmersos en ella.

A pesar de este predominio antropológico de los estudios de los grupos indígenas pobres, quisiera rescatar y recordar brevemente ocho libros que a mi criterio son pioneros y claves en las Ciencias Sociales en Guatemala. En su mayoría son macro-sociales tanto de Sociología, Economía e Historia. Todos ellos publicados en un momento histórico-teórico de las décadas de sesenta, setenta y ochenta cada uno con sus especificidades e intereses, pero que marcan una fase de las Ciencias Sociales guatemaltecas, aunque el tema de pobreza no es el tema central hay una sólida relación con ella.

El primero de Torres Rivas (1977) [1969] Interpretación del desarrollo social centroamericano: procesos y estructuras de una sociedad dependiente. Obra que se realiza con la influencia de la teoría de la dependencia, donde el autor discute la propuesta del proceso de industrialización en Centroamérica, estructura de clases sociales, el poder político, conflictos, la economía centroamericana en el contexto internacional, el mercado 
común y el ejército en el poder. El otro libro de importancia es de Guerra Borges (1986) [1969] Compendio de geografía económica y humana de Guatemala, un intento de relacionar geografía física, geografía humana y economía, un mapeo pionero de la situación del país, mostrando según sus datos las dificultades económicas y sociales de ese momento. El tercer libro es de Poitevin (1977) El proceso de industrialización en Guatemala, trabajo escrito en 1974, también con la influencia de la teoría de la dependencia. El libro se dedica al análisis de este proceso en la historia de Guatemala, desde la época liberal hasta los años setenta, donde se indica las alianzas y reacomodos de grupos de poder oligárquico y de los empresarios.

El cuarto libro corresponde a Martínez Peláez (1985) [1970] La patria del criollo: ensayo de interpretación de la realidad colonial guatemalteca, que el autor desde una perspectiva histórica, desarrolla la situación indígena en la época colonial como una clase social en interrelación con los criollos y ladinos. El quinto libro corresponde a Guzmán Böckler y Herbert (1970) Guatemala una interpretación histórico-social que vendría a provocar una polémica y debate sobre los grupos indígenas retomando las propuestas del culturalismo norteamericano de la sociedad dual, planteándose que la sociedad guatemalteca es formada por dos grupos: indígenas y ladinos pero en este caso tomados como clase social y que el conflicto es solamente entre ellos, los ladinos explotadores/dominadores y los indígenas los explotados/dominados. Esta dicotomía continua siendo defendida por algunos cientistas sociales hoy día, reduciendo el conflicto de clases sociales unicamente a estos dos grupos, dejando afuera otros grupos económicos que ostentan el poder y su relación con el capitalismo. Estas propuestas han provocado que la pobreza sea considerada solamente indígena y la riqueza sea ladina, dejando de lado que la pobreza abarca estos grupos y otros más.

El sexto libro es de Flores Alvarado (1973) [1968] La estructura social guatemalteca, el adamscismo y la sociedad guatemalteca que analiza la 
propuesta de Richard Adams y las diversas clases sociales dentro de la estructura social de Guatemala. El séptimo libro es el de Figueroa Ibarra (1980) El proletariado rural en el agro guatemalteco, libro escrito entre 1974 y 1975, trata de un análisis de la situación agraria en el país, los latifundios, minifundios, las políticas agrarias desde la época liberal, los diferentes tipos de proletarios y la relación índio-ladino en el agro. El octavo libro de Cambranes (1996) [1985] Café y campesinos: los orígenes de la economía de plantación moderna en Guatemala, 1857-1897, obra que consiste en el desarrollo de plantación del café como cultivo moderno, las políticas agrarias tanto conservadoras como liberales y su apoyo al cultivo, reclutamiento forzado de trabajadores, expropiación de tierras indígenas por parte del Estado para entregarlas a los cafetaleros y el desarrollo de las vías de comunicación para la exportación del café.

\section{Estudios generales macro-sociales: la pobreza como tema central}

La perspectiva teórica de los años sesenta a ochenta es sin duda la teoría del desarrollo y dependencia que proponía un dualismo entre, desarrollo/subdesarrollo, países ricos/países pobres no dependientes/ dependientes, economías centrales/economías periféricas, tradicional/moderno, campo/ciudad, urbano/rural; dualismos característicos de ese momento. En la definición del desarrollo prevalecen la distribución del ingreso entre países ricos y pobres, en cuanto otra tendencia indica que el subdesarrollo es un fenómeno de un proceso histórico estructural e institucional, Sunkel y Paz (1986) [1970]. La definición de desarrollo es compleja tiene innumerables facetas y puede ser vista desde varios ángulos, muy parecido a la definición de pobreza. El concepto de desarrollo lleva implícito varios aspectos, riqueza, evolución, progreso, crecimiento, industrialización y cambios. Las relaciones de dependencia de los países subdesarrollados de los países desarrollados pasa por las relaciones 
estructurales y económicas (Cardoso y Faletto (1988) [1969]. La necesidad del desarrollo de los países periféricos llevan a que las propuestas económicas se conviertan en políticas de desarrollo para América Latina principalmente la Alianza para el Progreso, Comisión Económica para América Latina y el Caribe CEPAL con las ideas de Raul Prebisch, el Mercado Común Centroamericano y más recientemente las políticas del Banco Mundial BM y el Fondo Monetario Internacional FMI.

Una segunda perspectiva de análisis es la teoría de la marginalidad, los estudios de marginalidad se remontan a la Escuela Sociológica de Chicago entre 1915-1935 que se dedican a estudiar al "hombre marginal" o sea el hombre que vive al margen de algo en este caso de la ciudad de Chicago en todas sus manifestaciones es el inicio de los estudios de pandillas, áreas marginales, asentamientos humanos, pobreza, migración y prostitución. Sin embargo después de la posguerra comienza a tener mayor fuerza teórica para definir a todo una masa fuera de una estructura económica lejos del proceso productivo. Los refinamientos de la marginalidad llegan hasta la segregación social y luego exclusión social que predomina en estos años pasando por el funcionalismo de Germani (1973) y de la discusión marxista de Perlman (1977), Quijano (1976) y Nun (2003), y la crítica a todos los anteriores de Bennholdt-Thomsen (1981).

Si mantenemos la propuesta de Mannheim, el escenario de la Guatemala de 1970-1990 ha estado en una crisis económica que se agudiza a finales del setenta, la política de sustitución de importaciones, la mecanización en el agro, el movimiento insurgente, dictadura militar, aumento de desempleo, políticas económicas erradas, represión, los problemas en el área rural y otros, son factores que en conjunto hicieron cada vez más visible la pobreza en el país poniendo en duda la democracia. Ante esta situación el fortalecimiento del sector oligárquico-agroexportador y su efecto la agudización de la pobreza en todo el país, se inician estudios macro-económicos con metodologías específicas de su área tanto del Esta- 
do como de otras instituciones para entender y conocer la situación económica surgiendo la pobreza como un tema a profundizar. Paralelamente a ello se investigan las clases populares y sus diversas manifestaciones estudiadas desde varias perspectivas disciplinares. A mediados de los ochenta es la época del aumento de los pobres por causa de las políticas de ajuste estructural.

En los años ochenta y noventa se desarrollan pocas investigaciones macro-sociales globales sobre la situación de la pobreza en Guatemala, son estudios iniciales de reflexión como veremos más adelante. Las características de la situación histórico, económica, política de Guatemala en esas décadas principalmente la del ochenta conocida como la "década perdida", muestra el agudo empobrecimiento del país. Es en este período que se incrementan las políticas de estabilización y ajuste estructural, para tratar de estabilizar la recesión económica que se vivía, junto con el incremento del conflicto armado y la aplicación de la política de sustitución de importaciones. Se produce la devaluación de la moneda, reducción de salarios, aumento del desempleo, discriminación y desigualdad.

En la década de 90 aparece la llamada nueva pobreza o pauperización creciente, surgida de los modelos neoliberales de privatización y el desempleo del sector público del Estado. Al inicio de esta misma década sucede una transición de dos temas de importancia regionales, como lo fueron los de economía informal (predominantes en los años 80 con estudios de caso micro-sociales) que en ese momento se encajan con la pobreza. Surgen así, dos libros que unifican ambos temas, Barrera (1992) Informalización y pobreza y (1993) La economía de los pobres, se puede decir que son dos libros de transición que vinieron a estimular el estudio de la pobreza. En esta misma dirección, Funkhouser y Pérez Saínz (1998) hacen una relación entre el mercado laboral y la pobreza en Centroamérica, siendo estudios más regionales, (tema a tratar más adelante).

Los estudios globales en estas dos décadas ochenta y noventa, puede decirse que abarcan áreas geográficas, desde la ciudad capital y el interior 
del país, principalmente los lugares más pobres, no obstante hay otros que aun quedan por estudiar como San Marcos y parte del Oriente. Las encuestas están distribuidas en casi todo el territorio nacional, puede decirse que la mayoría de investigaciones toman como técnica la encuesta de ingreso y consumo principalmente los estudios gubernamentales y centro de investigaciones internacionales. El resto de estudios se apoyan en resultados y datos publicados que les permite una interpretación de ellos. Entre los temas ejes de investigación predominan los económicos, principalmente la vertiente macro-económica de análisis de la pobreza en relación a los estudios sociológicos. En relación a la estructura, apoyo o respaldo institucional, predominan la Cooperación Internacional como el Banco Mundial, el PNUD, el BID, que también apoyan a universidades y centros de investigación y en alguna medida la infraestructura estatal la SEGEPLAN y el INE.

\section{Estudios de pobreza regionales}

En la década del noventa el tema de pobreza adquiere nuevo interés en su estudio a nivel centroamericano, es así que no podemos entender el estudio de la pobreza en Guatemala, sin el antecedente de otros estudios en países en Centroamérica. Se tiene claro que existen condiciones particulares en cada país, en donde la pobreza adquiere dimensiones diferentes. Es así que en un primer momento para 1990 se desarrollaron investigaciones con el apoyo de Agencia Canadiense para el Desarrollo Internacional ACDI y la FLACSO sede Costa Rica, que consistió en informes nacionales inéditos sobre la pobreza en Costa Rica, El Salvador, Guatemala, Honduras, Nicaragua y Panamá que fueron la base del libro La pobreza en América Central de Menjivar y Trejos (1990).

Posteriormente un segundo momento entre los años 1994-1995, se retoma el tema de pobreza a través de la FLACSO sede Costa Rica, con 
apoyo financiero de la Fundación Ford y del Real Gobierno de los Países Bajos se investigó la llamada nueva pobreza o los nuevos pobres o sea, los grupos que no eran pobres pero ahora están debajo de la línea de pobreza. Los estudios fueron: para Nicaragua Del Cid y Kruijt (1997), para Honduras Renzi (1997), y para Costa-Rica Sojo (1997). Otro intento de entender la pobreza en Centroamérica fue realizado por Fallas (1993) un estudio macro-económico más enfocado a la pobreza rural. Estos documentos pueden considerarse los primeros intentos de estudios de pobreza a nivel regional de Centroamérica, indicando la necesidad de investigaciones en cada uno de los países. ${ }^{2}$

\section{Estudios micro-sociales: la pobreza como contexto}

La perspectivas teóricas que en alguna forma tuvieron influencia son el de la economía informal y la cultura de la pobreza. La primera surge dentro de varios aspectos, según el Programa Regional del Empleo en América Latina y el Caribe PREALC que contiene: a) estrechez de mercados, mayor importación, b) contexto de transnacionalización, c) progreso técnico, d) menos espacio de venta, ya que el sector económico formal ocupa mayores espacios, e) desempleo, f) el salario no es la forma de remuneración, g) estructura económica heterogénea (Pérez Sáinz 1991).

\footnotetext{
2 El interés del debate sobre la pobreza en estos años hace que en 1996 la Revista Espacios n. 8 de la FLACSO sede Costa Rica, publique una serie de artículos sobre la pobreza y su relación con otros aspectos, como las políticas sociales, reducción de la pobreza, exclusión social, nueva pobreza, pobreza rural etc.
} 
La cultura de pobreza fue propuesta por el antropólogo Oscar Lewis, y es un desdoblamiento de la teoría de la marginalidad. La cultura de la pobreza lleva en si misma los procesos de socialización, psicología y su relación con la economía y la sociedad, un estado de perpetua penuria en relación con aspectos culturales, el pobre perpetua su propia pobreza porque no quiere salir de ella y se transmite de generación a generación (Perlman op.cit., p.148-153). Según ella, para Lewis la cultura de la pobreza tiene un sentido antropológico de normas, valores, conocimientos, adaptación al medio y símbolos. La propia falta de organización del pobre y de participación, lo lleva a una desorganización social, frente a una sociedad altamente organizada y compleja. En el modelo teórico de Lewis, no aparecen las relaciones de poder, de clase social ni de un capitalismo que provoca la misma pobreza, o de inadecuadas políticas económicas estatales, ni de los grupos de poder económico. Sin embargo esta propuesta ha sido y sigue siendo utilizada en las nuevas perspectivas de análisis del siglo XXI, que existe una cultura de los pobres y una cultura de los ricos.

En los últimos quince años han predominado los estudios microsociales de estudios de caso de los modos de vida de los grupos marginales, donde el tema de la pobreza es tocado tangencialmente. Son estudios sectoriales empíricos y descriptivos donde la pobreza es el trasfondo o contexto, pero no son investigaciones específicamente sobre pobreza como tema central, la misma es latente. No en tanto, la importancia de este tipo de estudios es que nos permiten una aproximación y conocimiento de las diversas manifestaciones y prácticas sociales de los grupos en pobreza y extrema pobreza. En la década de los ochenta por la situación de conflicto y de todas sus características económicas y políticas, los estudios microsociales ya estaban desarrollándose. Sin embargo es hasta los años noventa que en nuestra opinión existe un "boom" de los estudios, tanto de universidades (tesis), Estado, investigación independiente de Ongs (informes de consultorías), centros de investigación universitarios, centros de investigación mayas e centros internacionales ${ }^{4}$. Los espacios de investigación 
se centran en la ciudad capital y el interior del país. Me centraré en estudios que han tenido repercusión y han sido publicados por instituciones dedicadas a la investigación académica como indique antes, el cuerpo bibliográfico de los trabajos micro-sociales son bastante amplios. Otros estudios que se intensifican en la mitad de los años noventa son los que tratan de la cuestión étnica en áreas urbanas como son los grupos indígenas en la ciudad y su relación con la situación de desplazamiento por la guerra y su asentamiento en la capital.

Los temas ejes de investigación de los estudios micro-sociales varían. En este artículo me centré en los estudios que tratan de temas urbanos y están publicados. Pero es necesario reconocer que existen otros estudios e informes no publicados con una variedad de temas en los últimos 15 años, como asentamientos populares, cuestión indígena, derechos humanos, desempleo, desigualdad, discriminación, desastres, economía informal, género, migración, movimientos sociales salud (VIH/Sida), sector agrario, desarrollo sustentable, vivienda, violencia y otros.

\section{Los estudios de pobreza en los últimos años}

Después de la firma de paz en 1996, Guatemala está en el proceso de reconstrucción nacional, y el país se está reconociendo en todos sus aspectos. Desde finales de la década de 90 hasta la fecha, el estudio de la pobreza tiene mayor presencia en los niveles académicos y estatales. Esta preocupación se debe a la situación económica dejada por el gobierno anterior (2000-2004) donde el país está cada vez más pobre y sus índices de pobreza y pobreza extrema han crecido. Los diversos informes mundiales del BM, BID y PNUD, han mostrado una pobreza que cada vez es más crónica. La alarmante información que más de un tercio de la población en la región aproximadamente 180 millones de latinoamericanos, vive de dos dólares diarios (Yamada 2001, p. 2) provoca la búsqueda inmediata de 
estrategias de reducción de la pobreza.

La pobreza no es sólo definida por bajos ingresos o consumo, existe una interacción de otros factores como formas de socialización, la organización social, diversidad cultural cuestión étnica, salud nutrición, educación seguridad social, participación social y capacidad institucional, así como la nueva perspectiva teórica de la exclusión social constituida por tres dimensiones, económica, política y cultural (Gacitúa y Davis 2000, p. 13) tanto la pobreza como la exclusión social son procesos multidimensionales siendo esta la perspectiva teórica de análisis más reciente, utilizando por BM, BID, OIT, CEPAL y PNUD teniendo mayor aceptación. Sin embargo aun quedan algunas implicaciones de metodología por evaluar.

\section{Consideraciones finales}

Desde una perspectiva sociológica el Estado del arte de la investigación sobre pobreza en Guatemala mostró una serie de hallazgos interesantes que hacen repensar el tema. Las consideraciones finales de la investigación se basan en una muestra de los estudios que tratan la pobreza en diferentes formas, observando sus temas, aportes, innovaciones, inicio de una época o inicio de una línea de investigación.

El análisis del Estado del arte de los estudios de pobreza muestran las condiciones socioeconómicas en que se encuentran los grupos sociales en el país. Guatemala es un país con grandes desigualdades sociales, un Estado débil, políticas económicas equivocadas, y una situación social de deterioro y fragmentación. Aspectos que lleva a los grupos sociales vulnerables y grupos de poder a un paso lento en la construcción de una ciudadanía y democracia. 
Los estudios de pobreza tienen escasos alcances y considerables limitaciones, debido a que en su mayoría no son propositivos, se estudia la pobreza pero no hay mucha relación con la sociedad civil, no digamos un alcance en la creación de políticas sociales. Si bien son importantes y pertinentes en un país de grandes desigualdades y de una pobreza y pobreza extrema cada vez mayor, es necesario formar un cuerpo bibliográfico consistente. Sin embargo conociendo a los grupos sociales en pobreza, pueden construir formas alternativas de ciudadanía y conquistas sociales.

Sobre el número de estudios de pobreza, se puede indicar que es considerable, siempre y cuando teniendo en mente que no todos tratan específicamente sobre la pobreza. Las disciplinas que los estudian, puede decirse que son la Antropología, Sociología, Trabajo Social, aunque hay otras como la Historia y la Psicología. Estamos concientes que no se puede entender los estudios de pobreza alejados de la Ciencias Sociales y de los procesos históricos, políticos, económicos y sociales de Guatemala y la relación con otros campos de conocimiento en Centroamérica y América Latina. De igual forma el conocer la investigación sobre pobreza en Guatemala evidenció una realidad de exclusión social, desigualdad, discriminación y marginalidad de los sectores sociales más pobres, permitiendo la posibilidad de construir una ciudadanía y democracia.

El esquema de Mannheim de una sociología del conocimiento nos permitió entender el campo científico de la investigación sobre pobreza, tratando de mantener constantemente un puente con algunos de los aspectos históricos, sociales, económicos y políticos de Guatemala. Es así que la misma realidad nacional nos muestra caminos por recorrer en el estudio de la pobreza.

Según la muestra, los estudios sobre la pobreza, parecen haber experimentado cuatro transiciones, si bien que existe una constante simultaneidad de las investigaciones. En primer lugar, estudios macroeconómicos y macro-sociales tanto del Estado como del BM, el PNUD y otras instituciones que han permitido un conocimiento cuantitativo de la 
pobreza a través de las Encuestas Nacionales y los Informes de desarrollo humano, así como la investigación regional en Centroamérica sobre pobreza que han ampliado el campo disciplinar. En segundo lugar, estudios del ajuste estructural de las políticas de estabilización y su impacto en la población vulnerable. En tercer lugar, el constante aumento de estudios micro-sociales en varios temas, como ciudad y lo urbano, pobreza urbana, pobreza indígena y rural, economía informal, migración. La cuarta, corresponde a la situación actual de los estudios que se caracteriza por un mayor interés de la pobreza de varias instituciones que han organizado congresos, seminarios, talleres y encuentros. Que están promoviendo el uso de un esquema teórico-metodológico más orientado a la pobreza, sea cuantitativo como cualitativo para las nuevas investigaciones.

Si pensamos en la historia de larga duración, creo que tendríamos cuatro momentos que abarcaría la historia de los pobres en Guatemala de 1524-2004: Un primer momento serían los históricamente pobres desde la conquista, colonia, siglo XIX y la mitad del siglo XX. Un segundo momento sería la agudización de la pobreza en el país a finales de la década del setenta y toda la del ochenta con las Políticas de Ajuste Estructural que originaron el aumento de pobres y pobres extremos. Un tercer momento corresponde a los nuevos pobres de los años noventa procedentes de capas medias bajas, surgidos por el desempleo a nivel general por el uso desmedido de las políticas neoliberales de privatización de instituciones del Estado. Y finalmente los futuros pobres que vendrán con el proceso de empobrecimiento que provocarán el Tratado de Libre Comercio TLC y el Plan Puebla Panamá PPP.

Entre los aciertos y desaciertos se puede decir que la pobreza se investiga, pero son pocos los estudios que toman la pobreza como tema central. Sin embargo existen diversos estudios micro-sociales que tienen la pobreza como contexto y permite una aproximación a ella. Pero son desiguales y fragmentarios, no hay mucha continuidad, a pesar del esfuerzo 
de hacer investigaciones tanto en los ochenta como noventa. Son estudios precursores de reflexión que permite hacer un mapeo de las diversas manifestaciones de la pobreza en Guatemala. En cierto momento son simultáneos tanto los estudios de tipo macro-sociales como los microsociales y nos alertan por que caminos seguir.

Las perspectivas teóricas utilizadas consideramos que son las cinco propuestas indicadas a manera de argumento. Estos marcos conceptuales son factor fundamental en la determinación de los temas. Pueden ser simultáneos en determinado momento o ser substituidos por otros. Las metodologías que se emplean son variadas, pero predominan las del método cuantitativo de ingreso y consumo, y las que corresponden a las de medición de la pobreza empleados por los documentos oficiales y de organismos internacionales a nivel macro-económico y macro-social. Los métodos cualitativos de entrevistas en sus diferentes formas son más empleados por los estudios micro-sociales. Las limitaciones metodológicas que encontramos es la imposibilidad e incompatibilidad de comparar datos estadísticos, porque son obtenidos por métodos diferentes, no digamos la información obtenida por datos cualitativos. La pobreza como categoría social ha tenido un impulso intelectual con los estudios de organizaciones internacionales como el BM, el BID, la OIT, la CEPAL y el PNUD colocándola en los debates actuales en todos los países y Guatemala no está ajena a esta influencia. No obstante, considero que a pesar que existe un consenso generalizado acerca de los fundamentos teóricos de interpretación de la pobreza desde las perspectiva de estas instituciones, no implica que no queden problemas metodológicos por resolver.

En la muestra de los estudios, se puede notar que existen ciertos determinismos: a) de carácter conceptual una hegemonía de la perspectiva económica que reduce la pobreza a carencias e insuficiencias de ingresos y consumo, manteniéndose en la línea convencional que está imperando en las mediciones de pobreza, b) determinismos estructurales, que enfatizan el análisis de la pobreza vinculándola a indicadores de deterioro social y 
humano como un efecto de desarrollo económico altamente excluyente.

A pesar que predominan en un número considerable los estudios micro-sociales la mayoría son dispersos, parciales, descriptivos, puntuales y coyunturales sin pretensiones de analizar un contexto más amplio y complejo. Esta dispersión es por causa que no hay límites o líneas de investigación definidas o instituciones dedicadas directamente al estudio de la pobreza como han surgido en los últimos dos años. Las áreas geográficas que se estudian cada vez más abarcan todo el país, pero es importante aclarar que existe una línea de investigación fuerte en lo urbano, a través de algunas instituciones tanto universitarias como de investigación independiente.

Entre los aspectos temáticos se tienen algunos que se consolidan como: los temas urbanos, migración, cuestión étnica, desempleo. Otros sufren un estancamiento como la economía informal, cultura popular, asentamientos precarios y vivienda. Otros son relevantes y emergentes como: desastres y riesgo, genero, gestión municipal, Estado, políticas sociales, discriminación, equidad social y económica, racismo, salud, desarrollo sustentable, ciudadanía, medioambiente, educación, violencia, juventud y la influencia de la exclusión social y desigualdad. A pesar de estos, hay un déficit o ausencias de temas, que creo deberían estudiarse de aquí en adelante como: democracia, los pobres entendidos como sujetos históricos y actores sociales que participan de movimientos sociales, estrategias de sobrevivencia, redes sociales de parentesco y solidaridad, estructura productiva, desarrollo local y organización social, la política de descentralización, las municipalidades como instituciones de combate a la pobreza en sus municipios. Y el tema principal que sería la relación entre pobreza y globalización que debería ser un eje de investigación o denominador común, para entender en el marco de la globalización los impactos de los tratados de libre comercio que aumentarán la movilidad descenden- 
te de los pobres en la estructura social de la sociedad Guatemalteca.

Las instituciones involucradas en el apoyo a los estudios de pobreza muestran una estructura institucional y respaldo circunstancial y coyuntural de financiamiento de las investigaciones sea a través del Estado (trabajos oficiales de gobierno), Cooperación Internacional, organismos privados y las Ongs (informes de consultorías). Sin embargo si vemos el estudio de la pobreza como tema central o contextual, cronológicamente existe un avance o redescubrimiento de los años noventa en adelante, observándose un "boom" o impulso de los estudios con presencia institucional tanto del Estado como de investigación independiente por universidades, centros de investigación universitarios, centros de investigación mayas y centros internacionales. En relación a los investigadores o equipos de investigación por lo general son individuales, son mínimos los casos en que se contaba un equipo de investigación sobre pobreza, esto se observa más a nivel regional de Centroamérica. Sin embargo aún así son escasos los intercambios de investigadores así como de información.

Nos encontramos en un momento en que se tiene que hacer el esfuerzo de articular la investigación académica sobre pobreza, instituciones del Estado, sector privado y Cooperación Internacional. Es necesario convencer a las diversas instituciones de la importancia del estudio de la pobreza y trascender el pragmatismo inmediatista, corto placista y coyuntural y proponer posibles soluciones a mediano y largo plazo. Debe hacerse una reflexión crítica de pensar cuáles deben ser los esquemas teóricosmetodológicos más adecuados para la interpretación de las actuales condiciones que vive la región. La realidad guatemalteca y Centroamericana necesita un salto cualitativo en la investigación sobre pobreza. 
Cuatro tesis equivocadas de la comprensión de la pobreza en Guatemala

1. La pobreza en Guatemala no es solo indígena, existen otros grupos sociales aunque minoritarios dentro de ella principalmente en el oriente del país, norte y noroeste.

2. El mito y la continua confusión a nivel de Estado y Academia que en Guatemala existen dos grupos sociales antagónicos, indígenas y ladinos, los primeros pobres los segundos ricos. Esto muestra una ausencia total de una estructura de clases sociales, dejando de lado a los grupos de poder que se han enriquecido desde la colonia hasta hoy. O sea que la sociedad guatemalteca se reduce simplemente a ricos y pobres.

3. Estoy conciente que la pobreza y extrema pobreza está en el área rural, pero existe una pobreza urbana cada vez mayor y no solo en la macrocefalia de la ciudad capital, sino cada vez más en las ciudades secundarias donde crecen cinturones de marginalidad y pobreza urbana.

4. Se cree metodológicamente que la sumatoria mecánica de estudios micro-sociales de caso, permiten entender en un nivel macro-social la pobreza en vez de intentar entenderla como una totalidad.

\section{Referencias}

BARRERA, Yesid. et al. Informalización y pobreza. Costa Rica: FLACSO, 1992. BARRERA, Yesid. et al. La economía de los pobres. Costa Rica: FLACSO. 1993. BENNHOLDT-THOMSEN, Verónica. Marginalidad en América Latina: una crítica de la teoría. Revista Mexicana de Sociología, México, Vol. XLIII, № 4, p. 15051546. 1981.

CARDOSO, Fernando H. y FALETTO, Enzo. Dependencia y desarrollo en América Latina: ensayo de interpretación sociológica. 23ava. Edición. México: Siglo 
XXI. 1988 (1969).

CAMBRANES, Julio C. Café y campesinos: los orígenes de la economía de plantación moderna en Guatemala, 1857-1897. España: Editorial Catriel, 1996 (1985).

DEL CID, José y KRUIJT, Dirk. Los pobres aumentan: pobreza y gobernabilidad en Honduras. Costa Rica: FLACSO, 1997.

FALLAS, Helio. Centroamérica: pobreza y desarrollo rural ante la liberación económica. Universidad Nacional de Heredia. Costa Rica: Instituto Interamericano de Cooperación para la Agricultura IICA, 1993.

FIGUEROA IBARRA, Carlos. El proletariado rural en el agro guatemalteco. Guatemala: Editorial Universitaria de Guatemala USAC, 1980.

FLORES ALVARADO, Humberto. La estructura social guatemalteca, el Adamscismo y la sociedad guatemalteca. 2da. Edición.Guatemala: Editorial Piedra Santa, 1973 (1968).

FUNKHOUSER, Edward y PÉREZ SÁINZ, Juan Pablo (eds). Centroamérica en reestructuración: mercado laboral y pobreza en Centroamérica: ganadores y perdedores del ajuste estructural. Costa Rica: FLACSO, 1998.

GACITÚA, Estanislao y DAVIS, Shelton. Introducción: pobreza y exclusión social en América Latina y el Caribe. In: GACITÚA, Estanislao; SOJO, Carlos y DAVIS, Shelton (eds). Exclusión social y reducción de la pobreza en América Latina y el Caribe. Costa Rica:FLACSO-Banco Mundial. 2000. pp. 13-23.

GERMANI, Gino. El concepto de marginalidad: significado, raíces históricas y cuestiones teóricas, con particular referencia a la marginalidad urbana. Argentina: Ediciones Nueva Visión, 1973.

GOBIERNO de la República de Guatemala-Secretaría General de Planificación SEGEPLAN. Informe final: mapas de pobreza. Guatemala: SEGEPLAN, 2004.

GOBIERNO de la República de Guatemala-Secretaría General de Planificación SEGEPLAN. Perfil de la pobreza. Guatemala: INE, 2002.

GOBIERNO de la República de Guatemala-Secretaría General de Planificación SEGEPLAN. El drama de la pobreza en Guatemala: un informe sobre los rasgos de esta privación y sus efectos sobre la ciudad (versión preliminar para su discusión). Guatemala: Magna Terra, 2001a. 
GOBIERNO de la República de Guatemala-Secretaría General de Planificación SEGEPLAN. Mapas de pobreza: instrumentos para entender el flagelo de la pobreza en el país. Guatemala: SEGEPLAN, 2001b.

GOBIERNO de la República de Guatemala-Secretaría General de Planificación SEGEPLAN. Estrategia de reducción de la pobreza: un camino para la paz (propuesta de discusión). Guatemala: SEGEPLAN, 2001c.

GUERRA BORGES, Alfredo. Compendio de geografía económica y humana de Guatemala. 2da. Edición revisada y aumentada. Guatemala: Editorial Universitaria de Guatemala USAC, 1986 (1969).

GUZMÁN BÖCKLER, Carlos y LOUP HERBERT, Jean. Guatemala una interpretación histórico-social. México: Siglo XXI, 1970.

INSTITUTO Nacional de Estadística INE. Encuesta Nacional sobre Condiciones de vida -ENCOVI- 2000: La pobreza en Guatemala. Guatemala: INE, 2000.

INSTITUTO Nacional de Estadística INE. La encuesta Nacional de ingresos y gastos familiares -ENIGFAM- (1998-1999). Guatemala: INE, 1999.

LÓPEZ RIVERA, Oscar. Guatemala: intimidades de la pobreza. Guatemala: IDIESURL, 1999.

MANNHEIM, Karl. O problema de uma Sociologia do conhecimento. In: BERTELLI, Antônio R.; PALMEIRA, Moacir G. S.; VELHO, Otávio G. (organização e introdução). Sociologia do conhecimento. Rio de Janeiro: Zahar Editores, 1967. pp. 1380.

MARTÍNEZ PELÁEZ, Severo. La patria del criollo: ensayo de interpretación de la realidad colonial guatemalteca. 10ma. Edición. Costa Rica: EDUCA, 1985 (1970).

MENJIVAR, Rafael y TREJOS, Juan Diego. La pobreza en América Central. Costa Rica: FLACSO, 1990.

NOVAK, Mojka. Concepts of Poverty. In: OYEN, Else; MILLER, S.M. and ABDUS, Syed (eds). Poverty: a Global Review Handbook on International Poverty Research. Sweden: Scandinavian University Press/ UNESCO, 1997. pp. 47-61.

NUN, José. Marginalidad y exclusión social. México: Fondo de Cultura Económica, 2003.

PÉREZ JEREZ, Cristóbal. Guatemala: crisis y pobreza, los problemas económicos 
en la década de los 80. Guatemala: FLACSO-CSUCA-ICAP, 1987a. Informe de investigación no publicado.

PÉREZ JEREZ, Cristóbal. Guatemala hacia la pobreza. Economía, Guatemala, n. ${ }^{\circ}$ 92, p.1-41. 1987b.

PÉREZ SÁINZ, Juan Pablo. Informalidad urbana en América Latina: enfoques, problemáticas e interrogantes. Costa Rica: FLACSO y Editorial Nueva Sociedad, 1991.

PERLMAN, Janice. O mito da marginalidade: favelas e política no Rio de Janeiro. Rio de Janeiro: Editora Paz e Terra, 1977.

PROGRAMA de Naciones Unidas para el Desarrollo PNUD. Informe de desarrollo humano, Guatemala: una agenda para el desarrollo humano. Guatemala: Sistema de Naciones Unidas, 2003.

PROGRAMA de Naciones Unidas para el Desarrollo PNUD. Informe de desarrollo humano, Guatemala: desarrollo humano mujeres y salud. Guatemala: Sistema de Naciones Unidas, 2002.

PROGRAMA de Naciones Unidas para el Desarrollo PNUD. Informe de desarrollo humano, Guatemala: el financiamiento del desarrollo Humano. Guatemala: Sistema de Naciones Unidas, 2001.

PROGRAMA de Naciones Unidas para el Desarrollo PNUD. Informe de desarrollo humano, Guatemala: la fuerza incluyente del desarrollo humanos. Guatemala: Sistema de Naciones Unidas, 2000.

PROGRAMA de Naciones Unidas para el Desarrollo PNUD. Informe de desarrollo humano, Guatemala: el rostro rural del desarrollo humano. Guatemala: Sistema de Naciones Unidas, 1999.

PROGRAMA de Naciones Unidas para el Desarrollo PNUD. Informe de desarrollo humano, Guatemala: los contrastes del desarrollo humano. Guatemala: Sistema de Naciones Unidas, 1998.

POITEVIN, René. El proceso de industrialización en Guatemala. Costar Rica: EDUCA, 1977.

QUIJANO, Aníbal. Redefinición de la dependencia y proceso de marginalización en América Latina. In: WEFFORT, Francisco y QUIJANO, Aníbal (eds). Populismo, marginación y dependencia: ensayos de interpretación sociológica. Costa Rica: 
EDUCA, 1976. p. 171-329.

RELLO, Fernando. Instituciones y pobreza rurales en México y Centroamérica. Serie Estudios y perspectivas. № 2. México: CEPAL sede Subregional México, 2001. pp. 11-20.

RENZI, Maria Rosa. Los nuevos pobres: gobernabilidad y política social en Nicaragua. Costa Rica: FLACSO, 1997.

RUIZ, Carlos. Situación de la pobreza en Guatemala en la década del ochenta. Guatemala: FLACSO, 1990. Informe de investigación no publicado.

SIMMEL, Georg. El pobre. In: Sociología 2: estudios sobre las formas de socialización. España: Alianza Universidad, [1906] 1986. pp. 479-520.

SOJO, Carlos. Los de en medio: la nueva pobreza en Costa Rica. Costa Rica: FLACSO, 1997.

SPICKER, Paul. Eleven Definitions of Poverty. In: McNEISH John A. and OYEN, Else (ed and Comp). Approaching Poverty: Poverty Reduction for Practitioners. Sweden: CROP-ASDI, 2003. pp. 22-34.

SUNKEL, Osvaldo y PAZ, Pedro. El subdesarrollo latinoamericano y la teoría del desarrollo. 20ava. Edición. México: Siglo XXI, 1986 (1970).

TORRES RIVAS, Edelberto. Interpretación del desarrollo social centroamericano: procesos y estructuras de una sociedad dependiente. 5ta. Edición. Costa Rica: EDUCA, 1977 (1969).

YAMADA, Gustavo. Reducción de la pobreza y fortalecimiento del capital social y la participación: la acción reciente del Banco Interamericano de Desarrollo. Washington: D.C. BID, 2001. 


\section{Resumo}

Desde una perspectiva de la sociología del conocimiento de Karl Mannheim se puede comprender el estado del arte de los estudios de pobreza en Guatemala en un escenario entre 1980 y 2004. La justificación del trabajo se debe a la ausencia de una investigación que trate de entender el desarrollo del tema en las Ciencias Sociales en Guatemala y que demuestre su importancia a través de experiencias teóricas y metodológicas. Se puede decir que la investigación sobre la pobreza no ha sido sistemática ni continua debido al proceso social y político que ha vivido el país, no obstante se afirma con toda certeza que existe un corpus bibliográfico heterogéneo y considerable entre 1980-2004. La investigación tuvo como objetivo realizar un balance de las tendencias teóricas y metodológicas de los estudios en los últimos 20 años. Debo apuntar que la bibliografía sobre pobreza es bastante amplia e inevitablemente mereció seleccionar una muestra de los trabajos más representativos e innovadores, no sólo en las dos décadas analizadas, sino también en sus temas. No se puede entender los estudios de pobreza alejados de la Ciencias Sociales y de los procesos históricos, políticos, económicos y sociales de Guatemala y la relación con otros campos de conocimiento en Centroamérica y América Latina.

Palabras-clave: Pobreza, Ciencias Sociales, Sociología, Ciudadanía y Democracia. 


\section{Social Sciences, Sociology, and poverty in Guatemala}

\section{Edgar S. G. Mendoza}

From the perspective of Karl Mannheim's sociology of knowledge, it is possible to understand the state of the art of poverty studies in Guatemala between 1980 and 2004. This work is justified by the lack of investigations looking into the development of Social Sciences in Guatemala and it demonstrates its importance through theoretical and methodological experiences. Investigation on poverty can be said to have been neither systematic nor continued, due to the social and political process the country has undergone. Nevertheless, it can also be sustained that there is a heterogeneous and considerable bibliographic corpus between 1980-2004. This investigation aimed at a taking stock of the theoretical and methodological trends of the studies in the last 20 years. I shall point out that bibliography on poverty is quite broad and a selection of a sample of the most representative works was inevitable, not only in the decades examined, but also in terms of the issues. It is not possible to understand poverty studies detached from Social Sciences and historical, political, economic, and social processes of Guatemala and their relation to other fields of knowledge in Central America and Latin America.

Key words: poverty, social sciences, sociology, citizenship, democracy. 